\title{
P027. Idiopathic intracranial hypertension without papilledema in refractory chronic daily headache
}

\author{
Valentina Favoni ${ }^{1 *}$, Francesco Toni ${ }^{2}$ Sabina Cevoli ${ }^{1}$, Luigi Cirillo², Chiara La Morgia', Giulia Giannini', \\ Rossana Terlizzi ${ }^{1}$, Hana Privitera Hrustemovic ${ }^{1}$, Monica Messia ${ }^{2}$, Pietro Cortelli ${ }^{1}$, Giulia Pierangeli ${ }^{1}$
}

From Abstracts from the 1st Joint ANIRCEF-SISC Congress

Rome, Italy. 29-31 October 2015

\section{Background}

A diagnosis of idiopathic intracranial hypertension without papilledema (IIHWOP) should be considered in unresponsive chronic daily headache $(\mathrm{CDH})$ patients [1]. A CSF opening pressure (OP) above $200 \mathrm{~mm} \mathrm{H} 2 \mathrm{O}$ has been detected in chronic migraine patients with conflicting result, ranging from $10 \%$ to $86 \%$ of patients [1,2]. Moreover, controversies exist regarding the OP cut-off value greater than 200 or $250 \mathrm{~mm} \mathrm{H2O}$ and the role of transverse sinus stenosis (TSS) $[3,4]$.

\section{Aim}

To investigate the frequency of IIHWOP and TSS in adult patients with refractory $\mathrm{CDH}$.

\section{Methods}

In a prospective study, patients with refractory $\mathrm{CDH}$ underwent ophthalmologic evaluation and Optical Coherence Tomography to rule out the presence of papilledema; cerebral MR venography (MRV) to detect TSS; and a lumbar puncture to measure OP. In patients showing an $\mathrm{OP}<200 \mathrm{mmH} 2 \mathrm{O}$ the procedure was stopped after a $6 \mathrm{~mL}$ CSF withdrawal for routine analysis. In subjects with an OP $>200 \mathrm{~mm} \mathrm{H2O}$, intracranial pressure measurements were repeated every 2 $\mathrm{mL}$ of extracted CSF, up to about $100 \mathrm{~mm} \mathrm{H} 2 \mathrm{O}$. An MRV was repeated 1 month after LP in patients with $\mathrm{OP}>200 \mathrm{mmH} 2 \mathrm{O}$. TSS was identified using a combined conduit score (CCS).

\footnotetext{
* Correspondence: valentina.favoni2@unibo.it

'Department of Biomedical and NeuroMotor Sciences (DIBINEM) Alma Mater Studiorum-University of Bologna, IRCCS Institute of Neurological Sciences of Bologna, Bologna, Italy

Full list of author information is available at the end of the article
}

\section{Results}

Thirty-six patients were enrolled. Five patients were excluded due to protocol violations. Analyses were conducted in 31 patients $(24 \mathrm{~F}, 7 \mathrm{M}$; mean age $50.4 \pm 11$; mean BMI 26.5 \pm 6.5 ). None of the patients had papilledema. All displayed an OP lower than $250 \mathrm{~mm} \mathrm{H} 2 \mathrm{O}$ (range 102-245). Six patients (19\%) had an OP greater than $200 \mathrm{~mm} \mathrm{H} 2 \mathrm{O}$ : three of them achieved an improvement of headache frequency or intensity after 8-18 ml CSF withdrawal. Fifteen patients (48\%) had MRV evidence of TSS: bilateral in 4 and unilateral in 11. Using a Pearson's correlation coefficient test, no significant correlation between CCS and OP was found. After CSF withdrawal, no changes of CCS were found in the six patients who repeated MRV.

\section{Conclusions}

In our series, all patients displayed normal OP values $(<250 \mathrm{~mm} \mathrm{H} 2 \mathrm{O})$. Nineteen percent of patients had an OP greater than $200 \mathrm{~mm} \mathrm{H} 2 \mathrm{O}$. Our results confirm a low prevalence of IIHWOP in chronic headache sufferers. Moreover, the prevalence of sinus venous stenosis $(50 \%)$ was lower than previously described in unresponsive chronic headache patients $(92.8 \%)$, but similar to a series of unselected chronic headache patients (50.6\%) $[1,5]$. Transverse sinus stenosis seems not to correlate with CSF opening pressure, putting its role into question.

Written informed consent to publication was obtained from the patient(s).

\section{Authors' details}

'Department of Biomedical and NeuroMotor Sciences (DIBINEM) Alma Mater Studiorum-University of Bologna, IRCCS Institute of Neurological Sciences of 
Bologna, Bologna, Italy. ${ }^{2}$ Neuroradiology Department, IRCCS Institute of Neurological Sciences of Bologna, Bologna, Italy.

Published: 28 September 2015

\section{References}

1. De Simone R, Ranieri A, Montella S, Cappabianca P, Quarantelli M, Esposito F, Cardillo G, Bonavita V: Intracranial pressure in unresponsive chronic migraine. J Neurol 2014, 261(7):1365-1373.

2. Vieira DS, Masruha MR, Gonçalves AL, Zukerman E, Senne Soares CA, Naffah-Mazzacoratti Mda G, Peres MF: Idiopathic intracranial hypertension with and without papilloedema in a consecutive series of patients with chronic migraine. Cephalalgia 2008, 28(6):609-613.

3. Friedman DI, Liu GT, Digre KB: Revised diagnostic criteria for the pseudotumor cerebri syndrome in adults and children. Neurology 2013, 81(13):1159-1165.

4. De Simone R, Ranieri A, Montella S, Friedman DI, Liu GT, Digre KB: Revised diagnostic criteria for the pseudotumor cerebri syndrome in adults and children. Neurology 2014, 82(11):1011-1012.

5. Fofi L, Giugni E, Vadalà R, Vanacore N, Aurilia C, Egeo G, Pierallini A, Barbanti P: Cerebral transverse sinus morphology as detected by MR venography in patients with chronic migraine. Headache 2012, 52(8):1254-1261.

doi:10.1186/1129-2377-16-S1-A108

Cite this article as: Favoni et al:: P027. Idiopathic intracranial hypertension without papilledema in refractory chronic daily headache. The Journal of Headache and Pain 2015 16(Suppl 1):A108.

\section{Submit your manuscript to a SpringerOpen ${ }^{\mathcal{O}}$ journal and benefit from:}

- Convenient online submission

- Rigorous peer review

- Immediate publication on acceptance

- Open access: articles freely available online

- High visibility within the field

- Retaining the copyright to your article 